\title{
A Theoretical Analysis of the Contributions to the Internal Rotation Barrier in N-Benzylideneanilines
}

\author{
K. Figueroa A., M. Campos-Vallette, and R. Contreras R. \\ Department of Chemistry, Faculty of Sciences, University of Chile, Casilla 653, Santiago, Chile \\ Z. Naturforsch. 45a, 1199-1204 (1990); received July 4, 1990

\begin{abstract}
An analysis, using CNDO wave functions, has been carried out on the different contributions to
\end{abstract} \\ the internal rotation barrier in N-benzylideneaniline (1) and p-dimethylaminobenzylidene-p-nitro- \\ aniline (2) in several conformations. The stability of the different structures has been expressed in \\ terms of a partition of the total energy into electronic, net charges and steric hindrance contributions. \\ Based on the shape of the total energy surface it appears that the barrier composition may be \\ reasonably well described without approaching the absolute minimum. Rotation of the aniline group \\ in both molecules is mainly governed by steric hindrance. Rotation of the benzylidene group shows \\ a prevalent destabilizing electronic effect. The donor strength of the substituent in the benzylidene \\ ring seems to play an important role in stabilizing a less nonplanar structure.
}

Key words: N-benzylideneanilines, Semiempirical calculation, Energy partition and internal rotation.

\section{Introduction}

It is well known that the ultraviolet absorption spectrum of benzylideneanilines is remarkably different from those of the isoelectronic molecules stilbene and azobenzene [1]. It is now understood that the difference arises from the nonplanar conformation of $\mathrm{N}$-benzylideneanilines; structure determinations of compounds $\mathbf{1}$ and $\mathbf{2}$ indicate that the aniline and benzylidene rings are twisted out of the $\mathrm{C}_{1}-\mathrm{N}_{2}=\mathrm{C}_{3}-\mathrm{C}_{5}$ plane by varying angles in opposite directions $[2,3]$, see Fig. 1.

Berstein et al. [4] concluded from an ab-initio study that the ortho hydrogen interaction and the charge transfer from the nitrogen lone pair electrons (CT-1) are responsible for the noncoplanarity of compound $\mathbf{1}$. In p- and p'-substituted benzylideneanilines with an electron donor and acceptor, there occurs intramolecular charge transfer between these substituents (CT-2) $[5,6]$. The contribution of CT-1 to stabilization of the molecule increases with increasing twist angle $\Theta$; the smaller $\Theta$, the larger is the contribution of CT-2, see Figure 1.

The aim of this study is to isolate the relative contributions of factors such as electronic substituent effects as well as steric hindrance contribution to the stabilization of different structures in these molecules.

Reprint requests to Dr. M. Campos-Vallette, Facultad de Ciencias, Departamento de Quimica, Universidad de Chile, Casilla 653, Santiago, Chile.
At the CNDO/2 [7a] level, the stability of different conformations is expressed by partitioning the total energy $\left(E_{\mathrm{T}}\right)$ as follows [8]:

$$
\begin{aligned}
E_{\mathrm{T}}=\operatorname{Tr} \mathrm{PH} & +1 / 2 \sum_{A} \sum_{B} Q_{A} Q_{B} \tau_{A B} \\
& +1 / 2 \sum_{A} \sum_{B} Z_{A} Z_{B}\left(\tau_{A B}-1 / R_{A B}\right) .
\end{aligned}
$$

The first term of (1) represents the effective electronic energy $\left(E_{\mathrm{c}}\right)$. The second one represents the net charge contribution (NC) which accounts for the coulombic interaction energy between the partially charged atoms in the molecule; it depends on the net charge $Q_{A}$ and the Coulomb electronic interaction integral $\tau_{A B}$. The last term represents the steric hindrance effect $(\mathrm{SH})$. Further details concerning partition (1) are discussed in [9].

\section{Results and Discussion}

In Tables 1-4, the energetics for the internal rotation of compounds $\mathbf{1}$ and $\mathbf{2}$ are displayed. The relative quantities are referred to the corresponding planar structure (i.e. $\Theta=\Phi=0^{\circ}$ ), keeping the same standard geometry [10], in order to make significant comparisons.

For the $\mathrm{N}$-benzylideneaniline (1), Table 1 shows the energetics for the rotation of $\Theta$, keeping the $\Phi$ fixed (Figure 1). It may be seen that the calculation predicts the most stable rotamer at $\Theta=\pi / 2$. It is worth noticing, however, that this corresponds to a wide mini- 


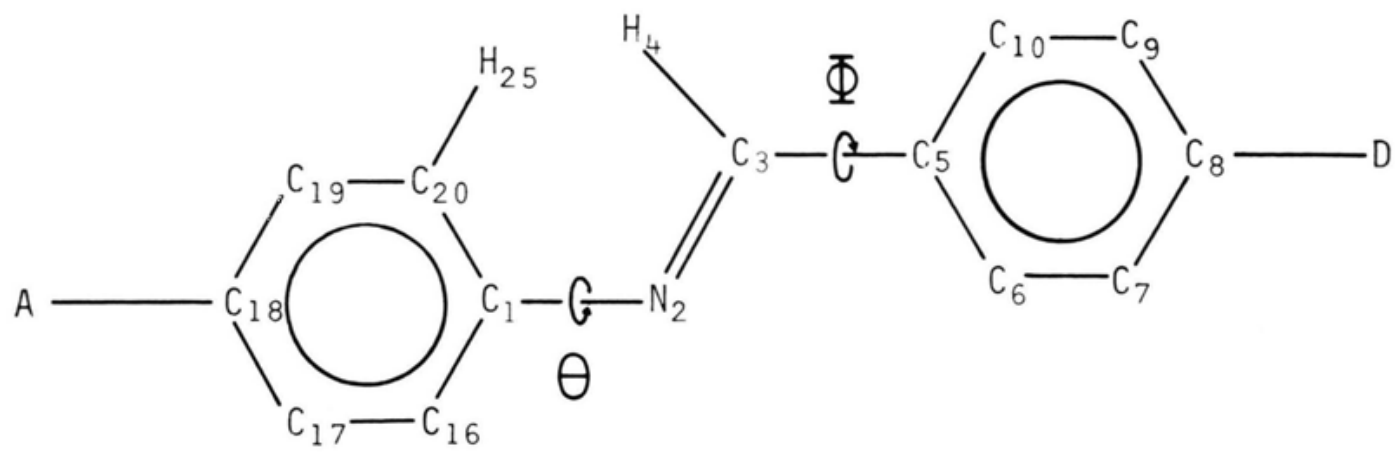

Fig. 1. N-Benzylideneanilines. Atom-numbering. 1: $A=D=H, 2: A=\mathrm{NO}_{2}, \mathrm{D}=\mathrm{N}\left(\mathrm{CH}_{3}\right)_{2}, \Theta=\mathrm{C}_{20} \mathrm{C}_{1} \mathrm{~N}_{2} \mathrm{C}_{1} \mathrm{~N}_{2} \mathrm{C}_{3}$, $\Phi=\mathrm{N}_{2} \mathrm{C}_{3} \widehat{\mathrm{C}_{5} \quad \mathrm{C}_{3}} \mathrm{C}_{5} \mathrm{C}_{6}$.

Table 1. Energies* for N-benzylideneaniline as a function of $\Theta$ with $\Phi=0^{\circ}$, including partitioning (see text).

\begin{tabular}{lcccccc}
\hline$\Theta$ & $E_{\mathrm{T}}$ & $=$ & $\delta E_{\mathrm{e}}$ & + & $\delta \mathrm{NC}$ & \\
\hline 10 & -0.58 & & -0.01 & -0.01 & -0.56 \\
20 & -1.91 & $=$ & -0.21 & -0.05 & -1.65 \\
30 & -3.34 & $=$ & -0.46 & -0.11 & -2.77 \\
40 & -4.40 & $=$ & -0.70 & -0.18 & -3.52 \\
50 & -5.08 & $=$ & -0.99 & -0.07 & -4.02 \\
60 & -5.45 & $=$ & -0.94 & -0.16 & -4.35 \\
70 & -5.63 & $=$ & -0.92 & -0.23 & -4.48 \\
80 & -5.73 & $=$ & -0.93 & -0.27 & -4.53 \\
90 & -5.75 & $=$ & -0.97 & -0.28 & -4.50 \\
\hline
\end{tabular}

* Relative energies, given here in kcal, are the differences between those for the conformation listed and the planar molecule $\Theta=\Phi=0^{\circ}$ (see text).

mum of about $6 \mathrm{kcal} / \mathrm{mol}$, which manifests itself for $\Theta$ in the region between $50^{\circ}$ and $130^{\circ}$, see Figure 2. Close to this region, the ab-initio minimum conformation reported by Berstein et al. is found: $\Theta=45^{\circ}$ and $\Phi=0^{\circ}$ [4]. It is precisely the shape of the total energy surface which allows us to perform the energy partition without working at the absolute minimum. Specifically, the energy partition for our minimum conformation $\Phi=30^{\circ}$ and $\Theta=90^{\circ}$ gives $\delta E_{\mathrm{e}}=-0.96, \delta \mathrm{NC}=-0.10$ and $\delta \mathrm{SH}=-4.77 \mathrm{kcal}$, which compares well with the partition corresponding to the ab-initio conformation: $\delta E_{\mathrm{e}}=-0.70, \delta \mathrm{NC}=-0.22$ and $\delta \mathrm{SH}=$ $-3.88 \mathrm{kcal}$. Furthermore, this prediction is consistent with experimental data in the gaseous state [2b]. The analysis based on (1) suggests that this relative stabilization with respect to the completely planar structure is mainly due to the relaxation of the steric hindrance contribution (compare Figs. 2 and 3), the $\mathrm{H}_{4} \cdots \mathrm{H}_{25}$ interaction being probably the major con- tribution to this effect. Since this predominant interaction is also present in stilbene, one would expect this molecule to display a conformation closer to that $\mathrm{N}$-benzylideneaniline (i.e. non planar). However, it seems that the $\mathrm{C}=\mathrm{C}$ bond in stilbene, instead of the $\mathrm{C}=\mathrm{N}$ function in $\mathrm{N}$-benzylideneaniline, increases the $\mathrm{H}_{4} \cdots \mathrm{H}_{25}$ distance, reducing the steric hindrance contribution. Table 1 also shows that there is no relevant contribution from the net charge term. However, the variation of the electronic contribution is significant since, starting from the $\Theta=50^{\circ}$ value, this term stabilizes around $1 \mathrm{kcal} / \mathrm{mol}$.

In order to give a more detailed picture of the electronic contribution to the rotation barrier, a comparison between the HOMO coefficients for molecule 1 is given in Figure 4. The following significant feature is observed: rotation of $\Theta$ causes the $\pi-\pi$ delocalization between $-\mathrm{N}=\mathrm{CH}-$ double bond and the aniline ring to decrease in favour of the $\pi-\pi$ delocalization between that bond and the benzylidene ring. This effect may also be seen from Table 1, where the electronic contribution suggests a slight stabilization induced by the non-planarity. This fact could be explained on the basis of an increase of the nitrogen lone pair electrons conjugation with the aniline system.

Table 2 shows the total relative energy variations of molecule 1 with respect to the rotation of $\Phi$ with $\Theta=0^{\circ}$. In this case a rather free rotation of the benzylidene ring is observed. Even though the numerical values do not permit to talk about a well defined minimum, the following relevant features may be stated: the soft stabilization observed around $\Phi=30^{\circ}$ contrasts with the well defined stabilization of the 
K. Figueroa A. et al. · Internal Rotation Barrier in N-Benzylideneanilines

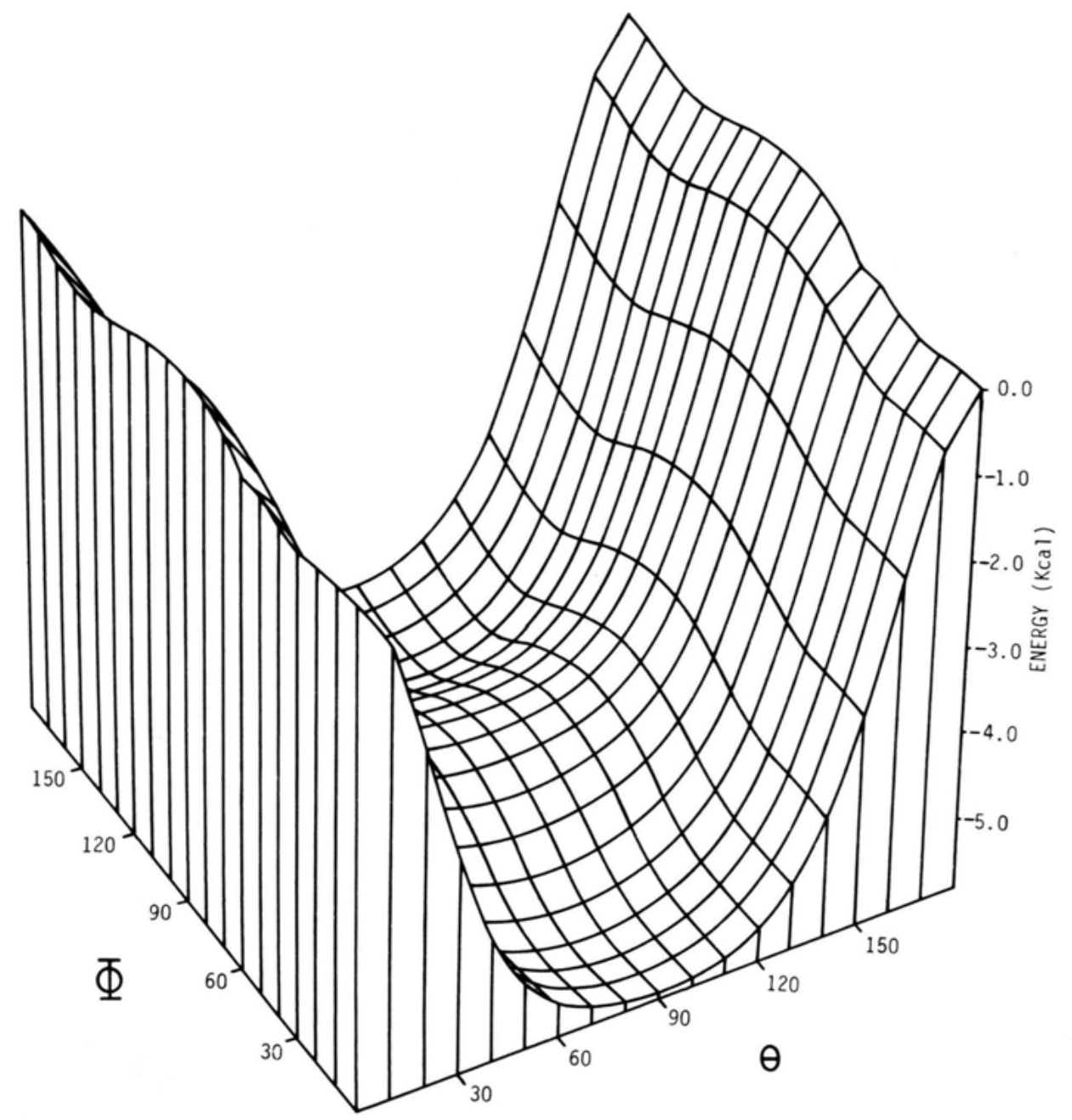

Fig. 2. Total energy in its dependence on $\Theta$ and $\Phi$.

Table 2. Energies* for $\mathrm{N}$-benzylideneaniline as a function of $\Phi$ with $\Theta=0^{\circ}$, including partitioning (see text).

\begin{tabular}{lrrrrrr}
$\Phi$ & $E_{\mathrm{T}}$ & $=$ & $\delta E_{\mathrm{e}}$ & + & $\delta \mathrm{NC}$ & \\
\hline 10 & -0.04 & & 0.06 & & 0.02 & -0.12 \\
20 & -0.11 & $=$ & 0.04 & 0.08 & -0.23 \\
30 & -0.17 & $=$ & -0.10 & 0.20 & -0.27 \\
40 & -0.15 & $=$ & -0.22 & 0.34 & -0.27 \\
50 & -0.05 & $=$ & -0.15 & 0.70 & -0.60 \\
60 & 0.08 & $=$ & -0.18 & 0.87 & -0.61 \\
70 & 0.19 & $=$ & -0.22 & 1.01 & -0.60 \\
80 & 0.27 & $=$ & -0.18 & 1.11 & -0.66 \\
90 & 0.30 & $=$ & -0.25 & 1.15 & -0.60
\end{tabular}

* See footnote Table 1.
$\Theta=\pi / 2$ rotamer. The flatness of the potential curve corresponds to the typical case of species stabilized by also consistent with electronic interaction. This is contribution, which the leading role of the net charge Also, we may observe that this most significant one. character.

In summary, the separated analysis for the rotation of the aniline and beparated analysis for the rotation former tends and benzylidene rings reveals that the and electronic stabilize out of the plane due to steric near the plane of the $-\mathrm{N}=\mathrm{CH}-$ system. This result 


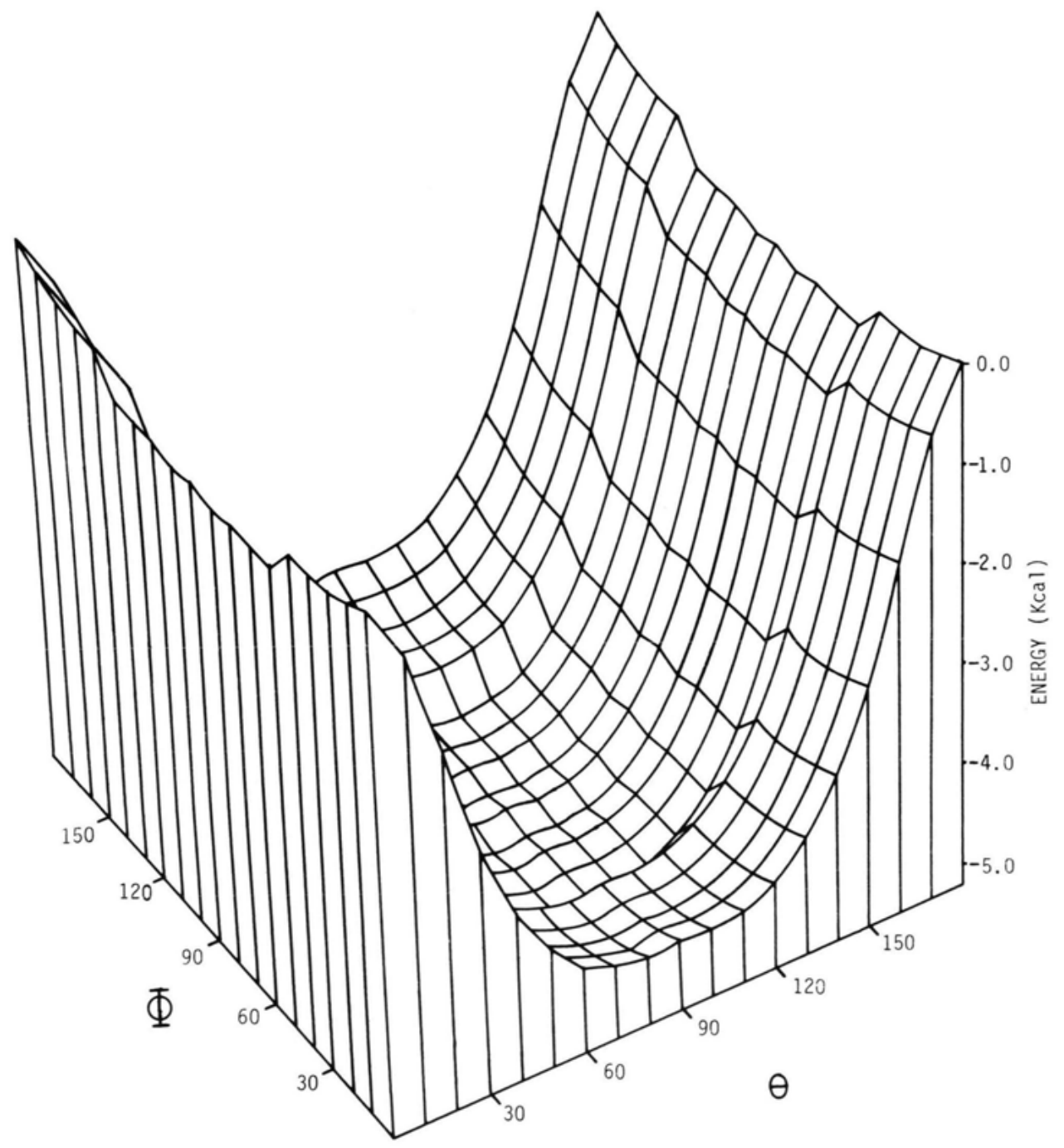

Fig. 3. Steric hindrance energy in its dependence on $\Theta$ and $\Phi$.

is consistent with the experimental conformation $\left(\Theta=55^{\circ}\right.$ and $\Phi=10.3^{\circ}$ in the solid, and $\Theta=52^{\circ}$ and $\Phi \equiv 0^{\circ}$ in the gas phase) reported for this system [2].

Table 3 shows the relative total energy variations with respect to the rotation of angle $\Theta$ in the p-dimethylaminobenzylidene-p-nitroaniline molecule $\mathbf{2}$. The motivation to include this system in the present study is twofold: a) it may serve as a model to study substituent effects on the rotation barrier of $\mathbf{1}$ already discussed and b) the nature of the substituent is known to induce interesting conformational changes in this birotator system $[3,5,6,11]$. First, it may be observed that in terms of total energy variations, the situation is rather similar to the rotation of $\Theta$ in $\mathbf{1}$; that is, a relative stabilization of about $6 \mathrm{kcal} / \mathrm{mol}$ is obtained in the region $50^{\circ}<\Theta<130^{\circ}$. Here again, the leading contribution comes from the steric hindrance effect, probably due to the same $\mathrm{H}_{4} \cdots \mathrm{H}_{25}$ interaction.

Concerning the electronic contribution $\left(E_{\mathrm{c}}\right)$, there are some significant features worth mentioning. First, in Table 3, second column, we observe, by comparing with the corresponding figures in Table 1 , a little attenuation of this contribution. This result may be explained by inspection of Fig. 4, where the HOMO coefficients (which also have a $\pi$ character) are smaller than those of the $\mathrm{N}$-benzylideneaniline molecule. However, rotation around the $\Theta$ does not significantly decrease the $\mathrm{C}_{1}-\mathrm{N}_{2}$ interaction. Overall, a more 

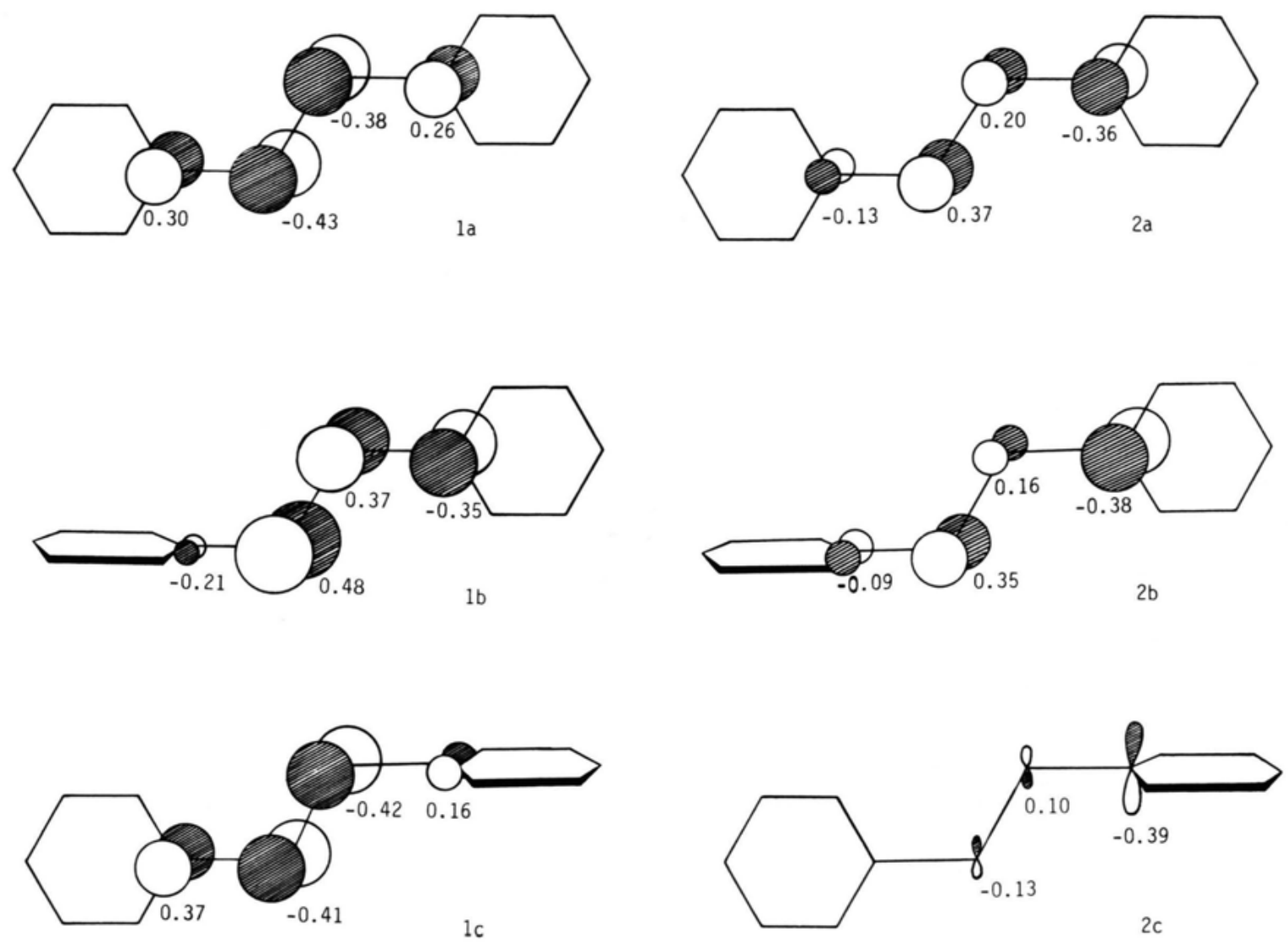

Fig. 4. HOMO coefficients diagram for the atoms $\mathrm{C}_{1}, \mathrm{~N}_{2}, \mathrm{C}_{3}$ and $\mathrm{C}_{5}$ in N-benzylideneaniline 1 and p-dimethylaminobenzylidene-p-nitroaniline 2. a) $\Theta=\Phi=0^{\circ}$, b) $\Theta=90^{\circ}, \Phi=0^{\circ}$, c) $\Theta=0^{\circ}, \Phi=90^{\circ}$.

Table 3. Energies* for p-dimethylaminobenzylidene-p-nitroaniline as a function of $\Theta$ with $\Phi=0^{\circ}$, including partitioning (see text).

\begin{tabular}{|c|c|c|c|c|c|c|c|}
\hline$\Phi$ & $E_{\mathrm{T}}$ & $=$ & $\delta E_{\mathrm{e}}$ & + & $\delta \mathrm{NC}$ & + & $\delta \mathrm{SH}$ \\
\hline 20 & $\begin{array}{l}-1.90 \\
-1.88^{a} \\
-1.96^{b}\end{array}$ & $=$ & $\begin{array}{l}-0.23 \\
-0.15 \\
-0.32\end{array}$ & & $\begin{array}{l}-0.08 \\
-0.08 \\
-0.05\end{array}$ & & $\begin{array}{l}-1.59 \\
-1.65 \\
-1.59\end{array}$ \\
\hline 40 & $\begin{array}{l}-4.36 \\
-4.28^{\mathrm{a}} \\
-4.56^{\mathrm{b}}\end{array}$ & $=$ & $\begin{array}{l}-0.65 \\
-0.39 \\
-0.96\end{array}$ & & $\begin{array}{l}-0.26 \\
-0.37 \\
-0.15\end{array}$ & & $\begin{array}{l}-3.45 \\
-3.52 \\
-3.45\end{array}$ \\
\hline 60 & $\begin{array}{l}-5.38 \\
-5.22^{a} \\
-5.74^{b}\end{array}$ & $=$ & $\begin{array}{l}-0.70 \\
-0.31 \\
-1.25\end{array}$ & & $\begin{array}{l}-0.43 \\
-0.57 \\
-0.24\end{array}$ & & $\begin{array}{l}-4.25 \\
-4.34 \\
-4.25\end{array}$ \\
\hline 80 & $\begin{array}{l}-5.65 \\
-5.43^{a} \\
-6.11^{b}\end{array}$ & $=$ & $\begin{array}{l}-0.56 \\
-0.19 \\
-1.24\end{array}$ & & $\begin{array}{l}-0.52 \\
-0.69 \\
-0.28\end{array}$ & & $\begin{array}{l}-4.57 \\
-4.55 \\
-4.59\end{array}$ \\
\hline
\end{tabular}

* See footnote Table 1.

a Molecule $\mathrm{Ph}-\mathrm{N}=\mathrm{CH}-\mathrm{Ph}-\mathrm{N}\left(\mathrm{CH}_{3}\right)_{2}$.

b Molecule $\mathrm{O}_{2} \mathrm{~N}-\mathrm{Ph}-\mathrm{N}=\mathrm{CH}-\mathrm{Ph}$.
Table 4. Energies* for p-dimethylaminobenzylidene-p-nitroaniline as a function of $\Phi$ with $\Theta=0^{\circ}$, including partitioning (see text).

\begin{tabular}{|c|c|c|c|c|c|c|c|}
\hline$\Phi$ & $E_{\mathrm{T}}$ & $=$ & $\delta E_{\mathrm{e}}$ & + & $\delta \mathrm{NC}$ & + & $\delta \mathrm{SH}$ \\
\hline 20 & $\begin{array}{r}0.04 \\
0.03^{a} \\
-0.14^{b}\end{array}$ & $=$ & $\begin{array}{l}0.30 \\
0.35 \\
0.01\end{array}$ & & $\begin{array}{r}-0.02 \\
-0.09 \\
0.08\end{array}$ & & $\begin{array}{l}-0.24 \\
-0.23 \\
-0.23\end{array}$ \\
\hline 40 & $\begin{array}{r}0.44 \\
0.39^{\mathrm{a}} \\
-0.25^{\mathrm{b}}\end{array}$ & $=$ & $\begin{array}{l}1.31 \\
0.73 \\
0.26\end{array}$ & & $\begin{array}{l}-0.56 \\
-0.03 \\
-0.24\end{array}$ & & $\begin{array}{l}-0.31 \\
-0.31 \\
-0.27\end{array}$ \\
\hline 60 & $\begin{array}{c}1.10 \\
1.03^{\mathrm{a}} \\
-0.10^{\mathrm{b}}\end{array}$ & $=$ & $\begin{array}{l}2.26 \\
1.54 \\
0.39\end{array}$ & & $\begin{array}{r}-0.47 \\
0.18 \\
0.11\end{array}$ & & $\begin{array}{l}-0.69 \\
-0.69 \\
-0.60\end{array}$ \\
\hline 80 & $\begin{array}{l}1.57 \\
1.49^{\mathrm{a}} \\
0.02^{\mathrm{b}}\end{array}$ & $=$ & $\begin{array}{l}2.67 \\
1.93 \\
0.32\end{array}$ & & $\begin{array}{r}-0.39 \\
0.27 \\
0.36\end{array}$ & & $\begin{array}{l}-0.71 \\
-0.71 \\
-0.66\end{array}$ \\
\hline
\end{tabular}

\footnotetext{
* See footnote Table 1.

a Molecule $\mathrm{Ph}-\mathrm{N}=\mathrm{CH}-\mathrm{Ph}-\mathrm{N}\left(\mathrm{CH}_{3}\right)_{2}$.

Molecule $\mathrm{O}_{2} \mathrm{~N}-\mathrm{Ph}-\mathrm{N}=\mathrm{CH}-\mathrm{Ph}$.
} 
extended $\pi$-delocalization, as compared with $\mathbf{1}$, is observed in the $\Theta=\pi / 2$ rotamer. In summary, the presence of the nitro group in the aniline ring seems to introduce a slight effect in the rotation.

In order to confirm the relevance of the electronic substituent effect on the conformation of this molecule, both donor and acceptor groups were removed, one at a time, to isolate local substituent effects. The results are included in Table 3, second and third entry. It may be seen that the observed trend is maintained even when both substituent groups are removed, confirming the predominant steric hindrance effect in this system.

Table 4 displays the variation of $\Phi$ for molecule 2 along with the results for $\mathrm{N}$-benzylideneaniline, in which we have removed both substituents. In this case, a very different picture is obtained. First, when twisting out of the plane, the system is destabilized mainly by electronic effects. The planar conformation of the benzylidene ring seems to be preferred.

For a better understanding of the prevalent electronic effect observed in this case, we represent the HOMO composition of the $\Phi=\pi / 2$ rotamer in Figure 4. Evidently a drastic change in the electronic situation is obtained: the only contribution of the $\mathrm{C}_{1}-\mathrm{N}_{2}=\mathrm{C}_{3} \mathrm{H}-\mathrm{C}_{5}$ subsystem to the $\mathrm{HOMO}$ of the molecule is the $2 \mathrm{py}\left(\mathrm{C}_{5}\right)$ orbital. There is no $2 \mathrm{pz}$ contribution to the HOMO since the $\pi$ interaction is broken by rotation. Thus, the natural explanation for the destabilization of the electronic leading contribution for the $\Phi=\pi / 2$ rotamer seems to be the decreasing conjugation ability of the $\mathrm{C}_{1}-\mathrm{N}_{2}=\mathrm{C}_{3} \mathrm{H}-\mathrm{C}_{5}$ group, probably induced by the strong influence of the donor

[1] J. Berstein, T. E. Anderson, and C. J. Eckhardt, J. Amer. Chem. Soc. 101, 541 (1979), and refs. therein.

[2] a) H. B. Burgi and J. D. Dunitz, Helv. Chim. Acta 53, 1747 (1970). - b) M. Traettberg, I. Hilmo, R. J. Abraham, and S. Ljunggren, J. Mol. Structure 48, 395 (1978).

[3] H. Nakai, M. Shiro, K. Ezumi, S. Sakata, and T. Kubota, Acta Crystallogr. Sect. B 32, 1827 (1976).

[4] J. Berstein, Y. M. Engel, and A. T. Hagler, J. Chem. Phys. 75, 2346 (1981).

[5] L. N. Patnaik and S. Das, Int. J. Quantum Chem. 27, 135 (1985). - L. N. Patnaik and S. Das, Bull. Chem. Soc. Japan 60, 4421 (1987).

[6] K. Figueroa A., R. Peña C., and M. M. Campos-Vallette, to be published. group $\mathrm{N}\left(\mathrm{CH}_{3}\right)_{2}$ in this conformation. The results of the calculations with removed substituents suggest that the nitro group has not a relevant effect on the rotation of the benzylidenic ring. However, the calculation with the dimethylamine group removed shows that the presence of this group is relevant to electronically stabilize a more planar structure.

The separated analysis for the rotation of the aniline and benzylidene group in $\mathbf{2}$ shows the following results:

a) Rotation of the aniline group seems not to be significantly affected by $\mathrm{NO}_{2}$ substitution. The electronic picture is rather similar to the N-benzylideneaniline case and, mainly, the stabilization of the $\Theta=$ $\pi / 2$ rotamer is governed by steric hindrance.

b) Rotation of the benzylidene group, however, is strongly different from the corresponding unsubstituted system. The result shows a prevalent destabilizing electronic effect for the rotation of this group.

Overall, we would expect a situation closer to planarity as the most stable conformation for this system, which is mainly induced by the donor strength of the p-substituent in the benzylidene ring.

\section{Acknowledgements}

This work has been supported by Grants No. 310, 493 and 623 from FONDECYT and Proyect 28158922 from Departamento Técnico de Investigación of the Universidad de Chile. We also thank to the SECI of the Universidad de Chile for providing free computer time.

[7] a) J. A. Pople and G. A. Segal, J. Chem. Phys. 44, 3289 (1966). - b) D. P. Santry and G. D. Pople, J. Chem. Phys. 47, 158 (1967).

[8] R. R. Contreras and J. S. Gomez, J. Phys. Chem. 88, 1905 (1984).

[9] J. S. Gomez and R. R. Contreras, Int. J. Quantum Chem. 30, 581 (1986).

[10] J. A. Pople and M. Gordon, J. Amer. Chem. Soc. 89, 4253 (1967).

[11] H. B. Burgi and J. D. Dunitz, Chem. Communications $1969,472$. 